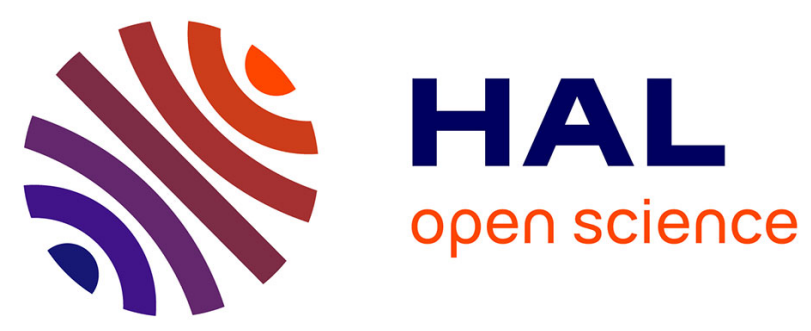

\title{
ONE-STEP SOLVENT EVAPORATION-ASSISTED 3D PRINTING OF PIEZOELECTRIC PVDF NANOCOMPOSITE STRUCTURES
}

Sampada Bodkhe, Gabrielle Turcot, Frederick Gosselin, Daniel Therriault

\section{- To cite this version:}

Sampada Bodkhe, Gabrielle Turcot, Frederick Gosselin, Daniel Therriault. ONE-STEP SOLVENT EVAPORATION-ASSISTED 3D PRINTING OF PIEZOELECTRIC PVDF NANOCOMPOSITE STRUCTURES. ACS Applied Materials \& Interfaces, 2017, 9 (24), pp.20833-20842. 10.1021/acsami.7b04095 . hal-03188306

\section{HAL Id: hal-03188306 https://hal.science/hal-03188306}

Submitted on 1 Apr 2021

HAL is a multi-disciplinary open access archive for the deposit and dissemination of scientific research documents, whether they are published or not. The documents may come from teaching and research institutions in France or abroad, or from public or private research centers.
L'archive ouverte pluridisciplinaire HAL, est destinée au dépôt et à la diffusion de documents scientifiques de niveau recherche, publiés ou non, émanant des établissements d'enseignement et de recherche français ou étrangers, des laboratoires publics ou privés. 


\section{ONE-STEP SOLVENT EVAPORATION-}

\section{ASSISTED 3D PRINTING OF PIEZOELECTRIC}

\section{PVDF NANOCOMPOSITE STRUCTURES}

SAMPADA BODKHE, GABRIELLE TURCOT, FREDERICK P. GOSSELIN AND DANIEL

THERRIAULT*

\section{AUTHOR ADDRESS}

Laboratory for Multiscale Mechanics, Department of Mechanical Engineering, Centre for Applied Research on Polymers and Composites (CREPEC)

Polytechnique Montreal,

C.P. 6079, succ. Centre-Ville, Montreal, QC H3C 3A7, Canada

KEYWORDS

3D printing, barium titanate nanoparticles, piezoelectric, polyvinylidene fluoride, sensors

\section{ABSTRACT}

The development of a 3D printable material system, possessing inherent piezoelectric properties, to fabricate integrable sensors in a single-step printing process without poling is of importance to the creation of a wide variety of smart structures. Here, we study the effect of addition of barium 
titanate nanoparticles in nucleating piezoelectric $\beta$-polymorph in 3D printable polyvinylidene fluoride (PVDF) and fabrication of the layer-by-layer and self-supporting piezoelectric structures at micro to millimeter scale by solvent evaporation-assisted 3D printing at room temperature. The nanocomposite formulation, obtained after a comprehensive investigation of composition and processing techniques, possesses a piezoelectric coefficient, $d_{31}$, of $18 \mathrm{pC} \mathrm{N}^{-1}$ which is comparable to typical poled and stretched commercial PVDF film sensors. A 3D contact sensor that generates up to $4 \mathrm{~V}$ upon gentle finger taps demonstrates the efficacy of the fabrication technique. Our one-step 3D printing of piezoelectric nanocomposites can form ready-to-use complex-shaped, flexible and lightweight piezoelectric devices. When combined with other 3D printable materials, they could serve as stand-alone or embedded sensors in aerospace, biomedicine and robotic applications.

\section{INTRODUCTION}

Polyvinylidene fluoride (PVDF) is the most piezoelectric polymer. Although PVDF's piezoelectric properties are lower than those of ceramics, it scores over them in terms of the inherent advantages of biocompatibility, toughness, flexibility, formability, and higher fatigue life. ${ }^{1}$ Among the various crystalline phases of PVDF, the electroactive $\beta$-phase (all trans) with a planar zig-zag form ${ }^{2}$ imparts the highest dipole moment, resulting in higher piezoelectric and ferroelectric constants. Unfortunately, PVDF commonly crystallizes into the thermodynamically stable non-polar $\alpha$-phase upon solidification, which does not possess the desired piezoelectric properties. The attainment of $\beta$-phase thus requires either one or more physical transformations via application of heat (annealing), ${ }^{3}$ large mechanical strain (stretching), ${ }^{4-6}$ large electric fields (poling) ${ }^{7-8}$ or filler addition. ${ }^{9-10}$ Fillers like carbon nanotubes,,${ }^{11-12}$ clay, ${ }^{13}$ cellulose, ${ }^{10}$ magnetic ${ }^{14}$ and piezoelectric nanoparticles (NPs) ${ }^{15}$ have proven to be very efficient in preventing the 
reversion of $\beta$-phase to $\alpha$-phase upon solidification. Addition of eco-friendly and biocompatible ${ }^{16-17}$ piezoelectric ceramic filler - barium-titanate $\left(\mathrm{BaTiO}_{3} \mathrm{NPs}\right)^{18-22}$ into PVDF has also shown to improve the ferro- and piezoelectric properties of PVDF without compromising its flexibility or strength. The incorporation of $\mathrm{BaTiO}_{3}$ NPs into PVDF has been attempted so far via sonication $^{21,23-24}$ and ball-milling ${ }^{25-26}$ approaches.

Commercially available piezoelectric sensors essentially possess flat or fiber-like configurations and hence are limited to the use of single piezoelectric coefficient only for electromechanical coupling. Three-dimensional (3D) printing of piezoelectric materials benefits from improved electromechanical response extractable from 3D designs. Such an improvement stems from the synergistic augmentation of both accessible strain and coupling between both the in-plane and out-of-plane piezoelectric coefficients, thereby increasing the voltage output and consequently the sensitivity of the device. ${ }^{27}$

For a piezoelectric sensor to be efficient, it will have to be integrated into the end-component. A multimaterial 3D printing process can result in elimination of the additional manufacturing step of sensor attachment, thereby serving as a long-term solution. In all the previously developed techniques for 3D printing of piezoelectric polymers such as fused deposition modelling of PVDF, ${ }^{28}$ optical printing of barium titanate $\left(\mathrm{BaTiO}_{3}\right)$ in a photoliable polymer, ${ }^{29}$ near-field electrospinning of PVDF, ${ }^{30,31}$ poling still dominates as an obligatory treatment. Further, the requirement of poling can be envisaged as a hindrance to achieve simultaneous integration of piezoelectric sensors during a multimaterial 3D printing process. The concern is aggravated when the adjacent material or substrate properties are adversely affected by the poling conditions (e.g., degradation or melting of the polymer structure). Therefore, the removal of the poling step will not only simplify the printing process but also at the same time allow: (i) multimaterial 
printing, (ii) conformal printing on sensitive materials or systems, (iii) new opportunities for creating piezoelectric structures with complex configurations.

In this work, we engineered a nanocomposite formulation to attain a combination of printability and piezoelectric properties close to that of commercial PVDF films without the requirement of poling. To achieve the nanocomposite formulation, we compared three different methods: ballmilling, extrusion mixing, and sonication, to incorporate varying concentrations of $\mathrm{BaTiO}_{3} \mathrm{NPs}$ in PVDF. The ability of the nanoparticles to nucleate and further retain the $\beta$-phase in PVDF is studied through custom designed piezoelectric tests and available characterization techniques: scanning electron microscopy (SEM), X-ray diffractometry (XRD), Fourier transform infrared photo-acoustic spectroscopy (FTIR-PAS), and impedance spectroscopy. The formulation showing the best piezoelectric properties is then utilized to form micro- to millimeter scale 3D features via solvent evaporation-assisted 3D printing. The process involves the dissolution of the nanocomposite into a highly volatile solvent followed by extrusion through a small nozzle under applied pressure. ${ }^{32-33}$ The rapid evaporation of the solvent results in retention of the desired shapes: layer-by-layer, self-supporting, and even freestanding structures. ${ }^{32}$ The application of our work is highlighted in the form of a ready-to-use millimeter scale 3D contact sensor fabricated in a single printing step.

\section{EXPERIMENTAL SECTION}

\section{Methods}

A mixture of acetone (BDH) and dimethylformamide (DMF; Alfa Aesar) was chosen as the solvent system for polyvinylidene fluoride (PVDF; Sigma-Aldrich). DMF is considered the least hazardous among the solvents used for PVDF and has a boiling point of about $153{ }^{\circ} \mathrm{C} .{ }^{34}$ On the other hand, acetone has a low boiling point $\left(\sim 56^{\circ} \mathrm{C}\right)$ but cannot dissolve PVDF. The ratio of 
DMF:acetone was experimentally optimized to 40:60 to minimize the amount of DMF while facilitating a quicker shape retention during printing. Dimethyl sulfoxide (DMSO; SigmaAldrich; $\left.65 \mathrm{~g} \mathrm{~L}^{-1}\right)$ was added as a $\beta$-phase initiating agent. ${ }^{35} \mathrm{PVDF}(2 \mathrm{~g})$ was sonicated with DMF (4 mL), acetone (6 mL), and DMSO $(0.6 \mathrm{~mL})$ for $20 \mathrm{~min}$ to form a $0.2 \mathrm{~g} \mathrm{~mL}^{-1}$ solution for printing. A similar solution was also used to fabricate a solution cast film for comparison.

\section{Barium titanate nanocomposite preparation $\left(0.2 \mathrm{~g} \mathrm{~mL}^{-1}\right.$ nanocomposite in the solvent mixture)}

Ball-mill mixing: A mixture of Barium titanate $\mathrm{NPs}\left(\mathrm{BaTiO}_{3} ; 99.9 \%\right.$ purity, $100 \mathrm{~nm}$; Nanostructured \& Amorphous Materials Inc.; $0.2 \mathrm{~g}$ ) and PVDF (2 g) was sonicated in DMF for 2 h. The solution was then mixed in a high energy shaker ball-mill (SPEX SamplePrep 8000 Series Mixer/Mill) at a rate of 1080 cycles per minute for 20 minutes. The number of zirconia balls for milling was chosen to match the weight of the solution. The solution was dried in a vacuum oven at $60{ }^{\circ} \mathrm{C}$ for $12 \mathrm{~h}$ to remove all the DMF. The dry nanocomposite $(2 \mathrm{~g})$ was later sonicated with DMF (4 mL), acetone (6 mL), and DMSO $(0.6 \mathrm{~mL})$ until complete dissolution of the nanocomposite was achieved. For apparent viscosity tests and printing 3D structures, $2.5 \mathrm{~g}$ and $3.0 \mathrm{~g}$ of the nanocomposite were dissolved to form 0.25 and $0.3 \mathrm{~g} \mathrm{~mL}^{-1}$ solutions, respectively.

Extrusion mixing: A mixture of $\mathrm{BaTiO}_{3} \mathrm{NPs}(0.2 \mathrm{~g})$ and PVDF $(2 \mathrm{~g})$ was fed into a $5 \mathrm{~mL}$ twin screw microextruder (Xplore) at $185^{\circ} \mathrm{C}$ and mixed for $5 \mathrm{~min}$. A temperature of $185^{\circ} \mathrm{C}$ was maintained above the melting point of $\operatorname{PVDF}\left(T_{m}=171^{\circ} \mathrm{C}\right)^{36}$ at both the inlet and exit of the extruder. The screw speed was $200 \mathrm{rpm}$. The mixture of PVDF and the NPs (2 g) obtained in the form of the filaments from the extruder was sonicated with a mixture of DMF $(4 \mathrm{~mL})$, acetone (6 $\mathrm{mL})$, and DMSO $(0.6 \mathrm{~mL})$ until complete dissolution of the nanocomposite was achieved. 
Sonication: $\mathrm{BaTiO}_{3} \mathrm{NPs}(0.18 \mathrm{~g})$ were added to DMF $(4 \mathrm{~mL})$ and sonicated for $3 \mathrm{~h}$ to achieve complete dispersion. PVDF (1.8 g) was completely dispersed separately in acetone $(6 \mathrm{~mL})$ via sonication. The two solutions were mixed, and DMSO $(0.6 \mathrm{~mL})$ was added and sonicated for 20 $\min$.

\section{Solvent evaporation-assisted 3D printing}

PVDF and its nanocomposite solutions were poured into a syringe $(3 \mathrm{~mL})$ and placed into a pneumatically operated dispensing system (HP-7X, EFD) to apply precise pressures for printing, as depicted in Figure 1a. This dispensing system was mounted on a robotic head (I\&J2200-4, I\&J Fisnar Inc.) controlled by a commercial software (JR Points for Dispensing, Janome Sewing Machine) that further enabled the deposition of the inks on a movable stage. The geometry of the profile to be printed was communicated to the robotic arm as a series of coordinates through the software. The air pressure from the dispenser forced the material out of the syringe through a nozzle. As the material escaped the nozzle, the evaporation of the solvents provides rigidity to retain the designed geometry. To fabricate one-dimensional (1D) filaments, two-dimensional (2D) films, and 3D layer-by-layer and self-supporting structures, different solution concentrations $\left(0.2,0.25\right.$, and $\left.0.3 \mathrm{~g} \mathrm{~mL}^{-1}\right)$ were used with a metallic nozzle (inner diameter $=100$ $\mu \mathrm{m})$ and varying extrusion pressures, $P(0.1$ to $2 \mathrm{MPa})$ and robot speeds $\left(0.5-20 \mathrm{~mm} \mathrm{~s}^{-1}\right)$. While fabricating films, the concentration of nanocomposite in the solvent mixture was kept at $0.2 \mathrm{~g}$ $\mathrm{mL}^{-1}$ and the printing parameters were as follows, unless mentioned otherwise: nozzle inner diameter $=100 \mu \mathrm{m} ; P \sim 1 \mathrm{MPa}$; robot speed $=20 \mathrm{~mm} \mathrm{~s}^{-1}$.

Characterization 
To fabricate the sensors, a thin conductive electrode layer was painted on both sides of the printed nano-composite films and the internal and external surfaces of the 3D cylinder with commercially available conductive silver paste (Sigma-Aldrich). Electrical connections were made using a conducting aluminum tape $(3 \mathrm{M})$.

To determine the linearity of the sensors, a dynamic mechanical analyzer (DMA; Q800; TA instruments) was further used in a single frequency $(45 \mathrm{~Hz})$ tension mode with a multistress force ramp of $0.1 \mathrm{~N}$ until fracture (rate of $\left.0.5 \mathrm{~N} \mathrm{~min}^{-1}\right)$. The sensors consisting of films $(20 \times 5 \times$ $0.1 \mathrm{~mm})$ with electrodes $(10 \times 5 \mathrm{~mm})$ were used with a grip separation of $\sim 10 \mathrm{~mm}$. Three samples were tested for each concentration of 5, 10, and $15 \mathrm{wt} . \%$ of NPs in the nanocomposites. Piezoelectric charges obtained from all the sensors were converted into voltages using a charge amplifier (Piezo lab amplifier, MEAS Specialties) in charge mode acquired with an NI-9239 data acquisition systemattached to a USB carrier NI-9162 (National Instruments) and recorded using a LabVIEW interface.

To obtain the diffractogram patterns of the films, a Philips X'pert diffractometer was used with scan angles from $10^{\circ}$ to $50^{\circ}$. A scan rate of $0.4^{\circ} \mathrm{min}^{-1}$ was used with a $\mathrm{Cu}$ target and $\mathrm{K}_{\alpha}$ radiation of $50 \mathrm{kV}$ and $40 \mathrm{~mA}$. FTIR-PAS (FTS 6000 spectrometer, Biorad) was used to obtain the absorption spectra of PVDF and its nanocomposite films in the range of $500-4000 \mathrm{~cm}^{-1} .128$ scans were conducted on each sample with a resolution value of $8 \mathrm{~cm}^{-1}$.

For viscosity characterization, five identical filaments were printed (nozzle diameter $=100 \mu \mathrm{m}$; speed $=0.5 \mathrm{~mm} \mathrm{~s}^{-1} ;$ printing time $\left.=120 \mathrm{~s}\right)$ at different pressures $(0.1-2 \mathrm{MPa})$ using $0.20,0.25$, and $0.30 \mathrm{~g} \mathrm{~mL}^{-1}$ of ball-milled PVDF/ $\mathrm{BaTiO}_{3}$ nanocomposite in the solvent mixture. End effects were neglected as the length to diameter $(L / D)$ ratio of the nozzle was greater than $50 .{ }^{37}$ The 
weights of the filaments were determined after $48 \mathrm{~h}$ to ensure complete evaporation of solvents. Mass flow-rates were calculated by reverting to the original mass before solvent evaporation. The apparent viscosity calculation details are provided in the Supporting Information and in Bruneaux et al. ${ }^{38}$

To image structures printed with the nanocomposites, optical microscopy (BX-61 Olympus microscope; Image-Pro plus V5, an image processing software from Media Cybernetics) was used. The morphology and cross-sections of the 3D printed films and structures were observed using a field emission scanning electron microscope (FE-SEM; JEOL JSM-7600TFE). A SEM (JEOL JSM 840) was used to obtain the images of the 3D printed structures at lower magnifications. Both SEMs were operated at an accelerating voltage of $10 \mathrm{kV}$. For viewing the cross-sections, the fibers and films were fractured in liquid nitrogen. All of the structures and films were gold-coated before imaging.

\section{RESULTS AND DISCUSSION}

Figure 1a is a schematic of the one-step solvent evaporation-assisted 3D printing of a piezoelectric nanocomposite contact sensor. The 70-layer cylindrical sensor shown in Figure 1b was printed with $0.25 \mathrm{~g} \mathrm{~mL}^{-1}$ of $10 \mathrm{wt} . \% \mathrm{BaTiO}_{3} \mathrm{NP}$ ball-milled nanocomposite solution. The programmed diameter and height of the cylinder were 5 and $7 \mathrm{~mm}$, respectively. After solvent evaporation, the printed cylinder shrunk to $\sim 3.1 \mathrm{~mm}$ in both height and outer diameter. The 3D contact sensor was used right after printing without the need for a poling step. The sensor was gently tapped with a forefinger (Figure 1b) five times consecutively, and the generated signal can be seen in Figure 1c. The sensor produced a consistent maximum voltage output of $\sim 4 \mathrm{~V}$ for touching and $\sim-2 \mathrm{~V}$ upon releasing (see Figure $\mathrm{S} 7$ for the detailed mechanism). The 3D sensor produced voltage approximately ten times higher than that of a film sensor of the same electrode 
surface area (Figure S6). The high voltage outputs from the 3D sensor presented here result from the improved inherent piezoelectric properties of PVDF by extrusion-based printing and the addition of $\mathrm{BaTiO}_{3} \mathrm{NPs}$. The contribution from interfacial charges to the response of the 3D sensor can be neglected as both the filler and the polymer used in this case are dielectrics, ${ }^{39}$ and nanoscale particles have a negligible contribution towards Maxwell-Wagner effects. ${ }^{40}$ Literature also suggests that addition of pristine $\mathrm{BaTiO}_{3}$ nanoparticles to PVDF does not result in interfacial polarization. ${ }^{41}$

In the following paragraphs, the effect of four parameters on the piezoelectric properties of PVDF are investigated: (i) extrusion-based printing, (ii) filler addition, (iii) processing techniques, and finally (iv) filler concentration. We use XRD and FTIR-PAS to study the effect of solvent evaporation-assisted 3D printing of PVDF on the conversion of its $\alpha$-phase into $\beta$ phase. ${ }^{42}$ The XRD patterns of solution-cast and 3D printed PVDF films prepared by using $0.20 \mathrm{~g}$ $\mathrm{mL}^{-1}$ PVDF in the solvent mixture can be observed in Figure 2a. Peaks pertaining to the $\alpha$-phase of PVDF at $18.70^{\circ}, 20.04^{\circ}$ and $26.50^{\circ}$ are clearly visible in case of the film fabricated via solution casting route, ${ }^{13,43}$ whereas a single distinct peak at $20.26^{\circ}$ corresponding to the $\beta$-phase confirms the effect of the extrusion pressures in the attainment of $\beta$-phase. As the polymer chains come out of the nozzle, the extrusion pressure of $\sim 1$ MPa leads to the significant phase transformation, and the passage through the relatively long slender nozzle $(12.7 \mathrm{~mm} ; L / D$ ratio $=$ 127) can align the polymer chains. We then carried out FTIR on the two kinds of films discussed above. Bands at 763 and $974 \mathrm{~cm}^{-1}$ are known to represent the presence of $\alpha$-phase, and those at 512,840 , and $1279 \mathrm{~cm}^{-1}$ the $\beta$-phase in PVDF ${ }^{44-46}$ As seen from a large drop in absorbance at $\sim 763 \mathrm{~cm}^{-1}$ in Figure $2 \mathrm{~b}$, the fraction of $\beta$-phase, $F(\beta)$, considerably increased upon 3D printing. 
The $F(\beta)$ in the 3D printed film (64\%), calculated using Beer-Lambert's law (Equation S2), was found to be $\sim 30 \%$ higher than that in the solution-cast film (49\%).

To further improve the $F(\beta)$ in PVDF, we incorporated $10 \mathrm{wt} . \% \mathrm{BaTiO}_{3} \mathrm{NPs}_{\text {into }}$ the PVDF matrix. We compared three mixing methods—-ball-milling, extrusion, and sonication-to determine which one had the most favorable impact on the piezoelectric voltage outputs resulting from the application of a dynamic mechanical load using the DMA. As the film-based sensors were subjected to longitudinal loads (direction 1), charges were generated across the thickness (direction 3) of the film (Figure S2c). The maximum voltage output was obtained with the sensors fabricated from the ball-milled nanocomposites (Figure S3a). For these sensors, the peak-to-peak voltage saturated at $6 \mathrm{~V}$ for frequencies higher than $35 \mathrm{~Hz}$. In comparison, the sensors fabricated by extrusion and sonication failed to give outputs distinguishable from the noise. In addition, there was no voltage output from a sensor fabricated by ball-mill mixing of 10 wt.\% $\mathrm{BaTiO}_{3}$ NPs with polylactic acid (PLA), which ascertains the fact that this process works due to the enhancement of $\beta$-phase in PVDF and not due to the piezoelectric properties of the NPs. Additionally, $\mathrm{BaTiO}_{3}$ is ferroelectric in nature and rendered piezoelectric only upon electric poling. This strengthens the fact that the piezoelectric response obtained in our material is purely from PVDF and has no contribution from the nanoparticles. ${ }^{47}$

We employed SEM and XRD characterization to understand why solely the ball-milled nanocomposites exhibited piezoelectricity. Figure 3a shows SEM image of $\mathrm{BaTiO}_{3} \mathrm{NPs}$. The size of the NPs varies between 80 and $100 \mathrm{~nm}$. The SEM images in Figure 3b-d show the morphology of the nanocomposites films. In the case of ball-milled nanocomposites (Figure 3b), large crystallites and pore sizes reveal higher crystal growth; a uniform dispersion of nanoparticle agglomerates (highlighted by circles) is also seen. It has been reported that 
dispersed agglomerates of NPs lead to an increased space charge density which in turn leads to higher piezoelectric properties. ${ }^{48}$ Non-uniformly distributed NP clusters are observed in the extruded nanocomposite (Figure 3c). There is more nucleation of crystallites in the sonicated nanocomposite (Figure 3d) as smaller spherulites are evident. Higher nucleation prohibits the growth of crystallites. ${ }^{9}$ The uniform dispersion of nanoparticles (seen as tiny white dots) in the sonicated nanocomposite is possibly the reason for this higher nucleation. Large micrometersized pores are present throughout the surface (Figure 3b) and cross section (Figure S4) of ballmilled nanocomposite films, whereas internal pores are very small or absent in the extrusionmixed and sonicated nanocomposites. The highly porous structure of ball-milled nanocomposites resulted in lower modulus as found by the mechanical tests (Figure S1b). Increased flexibility allows for soft sensor applications and reduced interference with sensed structures.

Figure 4a shows the X-ray diffractogram of the $\mathrm{BaTiO}_{3}$ NPs with characteristic peaks of $\mathrm{BaTiO}_{3}$ at $22.15^{\circ}, 31.53^{\circ}, 39^{\circ}$ and $45^{\circ} .{ }^{49}$ The splitting of peaks belonging to the (200) and (002) planes at $\sim 45^{\circ}$ indicates the presence of tetragonal crystal structure, which is essential for spontaneous polarization and thus, piezoelectricity. ${ }^{21,47,50}$ Figure $4 \mathrm{~b}$ shows the X-ray diffractogram of PVDF nanocomposites prepared by ball-milling, extrusion, and sonication. In the nanocomposite prepared by the ball-milling approach, the peaks at $18.70^{\circ}, 20.04^{\circ}$ and $26.50^{\circ}$ belonging to $\alpha$ phase of PVDF are absent. ${ }^{13,43}$ The presence of a single broad peak at 2-theta value of $20.26^{\circ}$ corresponding to the (200) and (110) planes $^{13,43}$ of $\beta$-phase underscores the inference that nanocomposite films prepared by ball-milling approach crystallized only in $\beta$-phase. In the case of the samples prepared by sonication, visible $\alpha$-peaks are found at $18.7^{\circ} .{ }^{13,43}$ A prominent $\alpha$ peak at $40^{\circ}$ and a $\gamma$-peak close to $26^{\circ}$ is seen in the extrusion-mixed sample. ${ }^{51-53}$ Uniformly dispersed individual nanoparticles in sonicated films were probably not as efficient as the 
agglomerates present in the ball-milled nanocomposites in preventing the reversion to $\alpha$-phase during the crystallization process. High temperature shear during extrusion shifted the $\mathrm{BaTiO}_{3}$ tetragonal peak at $45^{\circ}$, depicting a change from the tetragonal structure of $\mathrm{BaTiO}_{3}$ to a nonpiezoelectric cubic structure. ${ }^{54-55}$ This may be linked to the temperature used for melt-mixing, i.e. $185{ }^{\circ} \mathrm{C}$, which is higher than the $\mathrm{BaTiO}_{3}$ 's Curie temperature of $120{ }^{\circ} \mathrm{C} .{ }^{56} \mathrm{As}$ there is a change from noncentrosymmetric to a symmetric crystal lattice, the melt-mixed nanocomposites could not exhibit piezoelectricity. The properties of $\mathrm{BaTiO}_{3} \mathrm{NPs}$ seem to be unaltered by the ball-milling process as no change in their peak locations is observed.

After determining that ball-milling is the most appropriate mixing method in terms of piezoelectric properties, three different nanoparticle loadings (5, 10, and $15 \mathrm{wt} . \%)$ were investigated to determine the optimum filler weight fraction to fabricate 3D sensors. The voltage responses from the single frequency scans observed in Figure 5 are linear with the force until fracture, as should be the case with piezoelectric materials. The voltage outputs initially increased from 5 wt. $\%$ of $\mathrm{BaTiO}_{3}$ to $10 \mathrm{wt} . \%$. However, the nanocomposite sensors with 15 wt. $\%$ of the fillers exhibited no considerable output. A maximum peak-to-peak voltage around $2.8 \mathrm{~V}$ was obtained at a force of $2.7 \mathrm{~N}$ for the sensor with $10 \mathrm{wt} . \%$ fillers.

Impedance spectroscopy was used to calculate the dielectric constants of the sensors. The nanocomposites with $10 \mathrm{wt} . \%$ NP loading possessed the highest dielectric constant of $\sim 210$ (Table S2). The piezoelectric coefficient is the ratio of electric field produced in a piezoelectric material to the applied stress. Average piezoelectric coefficients $d_{31}=2.5$ and $18 \mathrm{pC} \mathrm{N}^{-1}$ were obtained for ball-milled nanocomposite sensors with 5 and $10 \mathrm{wt} . \% \mathrm{BaTiO}_{3} \mathrm{NPs}$, respectively (calculated using the voltage values as in Figure 5 and Equation S1). The value of $18 \mathrm{pC} \mathrm{N}^{-1}$, 
obtained here without any poling is comparable to that of typical commercial stretched and poled PVDF-based film sensors $\left(23 \mathrm{pC} \mathrm{N}^{-1}\right) \cdot{ }^{57}$

We further use the results from SEM, XRD, and FTIR to understand the performance of our ballmilled nanocomposites. Figure 6a-c are SEM images of 5, 10, and 15 wt.\% of $\mathrm{BaTiO}_{3} \mathrm{NPs}_{\text {in }}$ PVDF via ball-milling. Fewer number of agglomerates are found in the case of the $5 \mathrm{wt} . \%$ loading compared to that found in the $10 \mathrm{wt} . \%$. Although the number of agglomerates is increased in the $15 \mathrm{wt} . \%$ loading, their average size is almost halved in comparison to the 10 wt.\% loading. This establishes that there has to be an optimum size and number of agglomerates to effectively prevent the reversion to $\alpha$-phase. The XRD results (Figure S5) depicted that the films prepared with $10 \mathrm{wt} . \% \mathrm{NP}$ loading exhibited no other phases than $\beta$-phase, while the other two films crystallized additionally in $\alpha$ - or $\gamma$-phase or both.

FTIR-PAS was employed to explain the difference between the piezoelectric constants of the 5 and 10 wt.\% nanocomposites. Figure $6 \mathrm{~d}$ shows the FTIR spectra of the 5 and $10 \mathrm{wt} . \%$ ballmilled nanocomposite films. A clear decrease in the content of $\alpha$-phase can be observed in the curve pertaining to $10 \mathrm{wt} . \%$ nanoparticle loading. Beer-Lambert's law was used to quantify this difference in the amount of the two phases in the nanocomposites. The $F(\beta)$ present in the 5 and 10 wt.\% ball-milled nanocomposites was 68 and 78\%, respectively (Equation S2). The higher value of $F(\beta)$ in the $10 \mathrm{wt} . \%$ nanocomposites explains the improved response and higher piezoelectric coefficient value. The Beer-Lambert law could not be applied to the $15 \mathrm{wt} . \%$ loaded nanocomposite (data not shown) due to the presence of additional $\gamma$-phase as seen from the XRD (Figure S5). 
Piezoelectric fillers do not contribute to the overall piezoelectricity of the nanocomposite when used in very small quantities, which was the case until $10 \mathrm{wt} . \%$ loading. ${ }^{58}$ Hence, the increased presence of $\beta$-phase in PVDF upon the addition of $10 \mathrm{wt} . \%$ NPs via ball-milling is attributed to the mechanical activation of the NPs and their dispersed agglomerates, leading to an increased dipole moment. ${ }^{26,48}$ Further, given that the piezoelectric coefficients of the filler and the polymer have different signs, poling in a single direction would cancel out the $d_{31}$ coefficients. ${ }^{59}$ Hence, our approach to orient dipoles without the application of any electric field serves to improve the inherent piezoelectric properties in PVDF at low mass fraction. Lower effective Young's modulus in the case of the ball-milled nanocomposites as compared to that in the other two nanocomposites (Figure S1b) resulted in increased sensitivity. ${ }^{60}$ However, as the process relies on improving the inherent piezoelectric properties of the polymer, factors such as humidity, temperature, print directions, speeds, and pressures can have a strong effect on the properties and hence reproducibility. Thus, efforts are being made to optimize these parameters and will form a part of our future work.

We propose the following hypothesis to summarize the process of formation of aligned $\beta$-phase chains during 3D printing. As seen in Figure 7, the addition of $\mathrm{BaTiO}_{3} \mathrm{NPs}$ to PVDF via ballmilling led to increased activation $\operatorname{sites}^{61-62}$ on the NPs acting as $\beta$-phase nucleating sites because of the strong $\mathrm{O}-\mathrm{H} \cdots \mathrm{F}-\mathrm{C}$ hydrogen interaction at the $\mathrm{PVDF} / \mathrm{BaTiO}_{3}$ interfaces.${ }^{63}$ These interactions combined with the dipolar interactions of polar DMF and PVDF resulted in $\mathrm{CH}_{2}-\mathrm{CF}_{2}$ dipoles as in the case of all trans structure of $\beta$-phase. Moreover, the dipole alignment in our work is attained through mechanical means and not from conventional electrical poling. ${ }^{64}$ The extensional flow of the solution resulted in the required chain and dipole alignment. ${ }^{65-66}$ Indeed, the high pressures ( $\sim 1 \mathrm{MPa}$ ) during the passage through the fine nozzle with a high $L / D$ ratio 
$(\sim 120)$ and post-extrusion stretching due to higher velocities of the robotic motion $\left(\sim 20 \mathrm{~mm} \mathrm{~s}^{-1}\right)$ contributed to align the PVDF polymer chains. The sub-micron sized agglomerates further prevented any chances of reversion to $\alpha$-phase. ${ }^{40}$ In the absence of electric poling, the

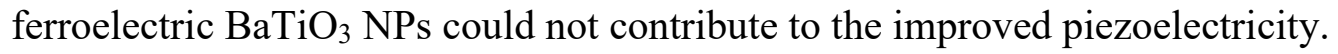

The shape and thickness of the extruded material from the nozzle during the printing process predominantly depends on the relationship between the applied pressure and the relative velocity of the robotic arm over the stage. Thus, to attain the required geometry, it is essential to arrive at the optimal relationship between the extrusion pressure and the velocity of the arm movement via a rheological analysis. ${ }^{33}$ Rheological characterization allows us to establish the dependence of apparent viscosity on the extrusion pressure and the printing speed. The former is proportional to the shear stress at the wall, whereas the latter relates to the shear rate during the printing process. Figure 8 shows the process-related viscosity as a function of the applied shear rates. The viscosity range for the three different concentrations $\left(0.2,0.25\right.$, and $0.3 \mathrm{~g} \mathrm{~mL}^{-1}$ of ball-milled $\mathrm{PVDF} / \mathrm{BaTiO}_{3}$ nanocomposite) is found to be between 0.1 and 2.7 $\mathrm{Pa}$ s. The viscosity decreases with increasing shear rate, characteristic of a shear thinning behavior. ${ }^{67}$ This property is essential for a material to be employed in extrusion-based printing processes. The optimal viscosity for a material is low enough to be extruded out of the small nozzle but at the same time high enough for shape retention after extrusion. ${ }^{68}$ Thus, the rheological properties of the inks are well-suited for $3 \mathrm{D}$ printing. Moreover, it can be observed that the viscosity of the inks significantly increases with the concentration of the nanocomposites in the solutions aiding the fabrication of 3D selfsupporting structures due to the increased rigidity.

The viscosity study aided in determining the optimum concentrations of the ball-milled PVDF nanocomposite required to obtain 1D, 2D, and 3D shapes, as shown in Figure 9. We can see a 
SEM image of the cross-section of a 1D filament (Figure 9a) extruded using $0.3 \mathrm{~g} \mathrm{~mL}^{-1}$ nanocomposite solution with a $100 \mu \mathrm{m}$ nozzle at $\sim 2.6 \mathrm{MPa}$. The average diameter of the fiber after complete evaporation of the solvents was about $56 \pm 6 \mu \mathrm{m}$. The reduction in diameter of the fiber and the rough surface upon extrusion is attributed to evaporation of the solvents postextrusion. A loading of $0.2 \mathrm{~g} \mathrm{~mL}^{-1}$ of nanocomposite in the solution mixture was observed to be optimal for printing 2D films and patterns without voids or gaps. A 2D pattern (LM2, Figure $9 \mathrm{~b}$; the abbreviation of our laboratory) was printed using $0.2 \mathrm{~g} \mathrm{~mL}^{-1}$ solution with a pressure of $\sim 0.11 \mathrm{MPa}$ and robot velocity of $10 \mathrm{~mm} \mathrm{~s}^{-1}$. A concentration of $0.25 \mathrm{~g} \mathrm{~mL}^{-1}$ facilitated the formation of 2.5D layer-by-layer structures: a circular cylinder (Figure 9c) printed at $\sim 0.48 \mathrm{MPa}$ and $1 \mathrm{~mm} \mathrm{~s}^{-1}$. The cylinder has 70 layers and a programmed diameter and height of 5 and $7 \mathrm{~mm}$, respectively. The concentration of $0.3 \mathrm{~g} \mathrm{~mL}^{-1}$ of the nanocomposite was best to print spanning or self-supported structures such as 3D scaffolds. A 9-layer scaffold (Figure 9d) was printed at $\sim 1.3$ MPa and $13 \mathrm{~mm} \mathrm{~s}^{-1}$ using a $100 \mu \mathrm{m}$ nozzle with clearly distinguishable self-supporting filaments and individual layers. The spanning distance between two consecutive parallel filaments is 10 $\mathrm{mm}$.

\section{CONCLUSION}

Fusion of the solvent evaporation-assisted 3D printing and our piezoelectric material results in two critical achievements: (i) genesis and stabilization of electroactive $\beta$-phase, leading to remarkable sensing and actuation characteristics at room temperature, and (ii) optimized rheology to fabricate self-supporting structures with satisfactory mechanical robustness, all without the need for additional electromotive (poling) treatment. High dielectric and piezoelectric properties were obtained via 3D printing of a nanocomposite solution of $10 \mathrm{wt} . \%$ $\mathrm{BaTiO}_{3}$ NPs ball-milled with PVDF due to the prevalence of $\beta$-phase. A piezoelectric coefficient 
of $18 \mathrm{pC} \mathrm{N}^{-1}$ comparable to that found in commercial PVDF sensors was obtained. A fully functional 3D printed sensor generating a maximum voltage output of up to $4 \mathrm{~V}$ upon finger tapping was fabricated and demonstrated. The one-step 3D printing of piezoelectric materials opens up a new demographic of sensor designs that is more integrable, conformable, scalable, versatile, and application-oriented. Apart from sensing, 3D piezoelectric scaffolds fabricated by the shown process could be used as electroactive scaffolds in tissue engineering, ${ }^{69}$ providing a biomimetic environment for cell culture. Given the limitation of the conventional electrode deposition techniques (forming planar electrodes), there is a need to develop a hybrid process to print the electrodes along with the polymer, thereby, delivering the entire sensor in a single step. The sensors produced in the single step could be used as hair-like sensors for aerodynamics, as embedded sensors in aerospace or biomedical prosthesis, and as filaments for smart textiles. 

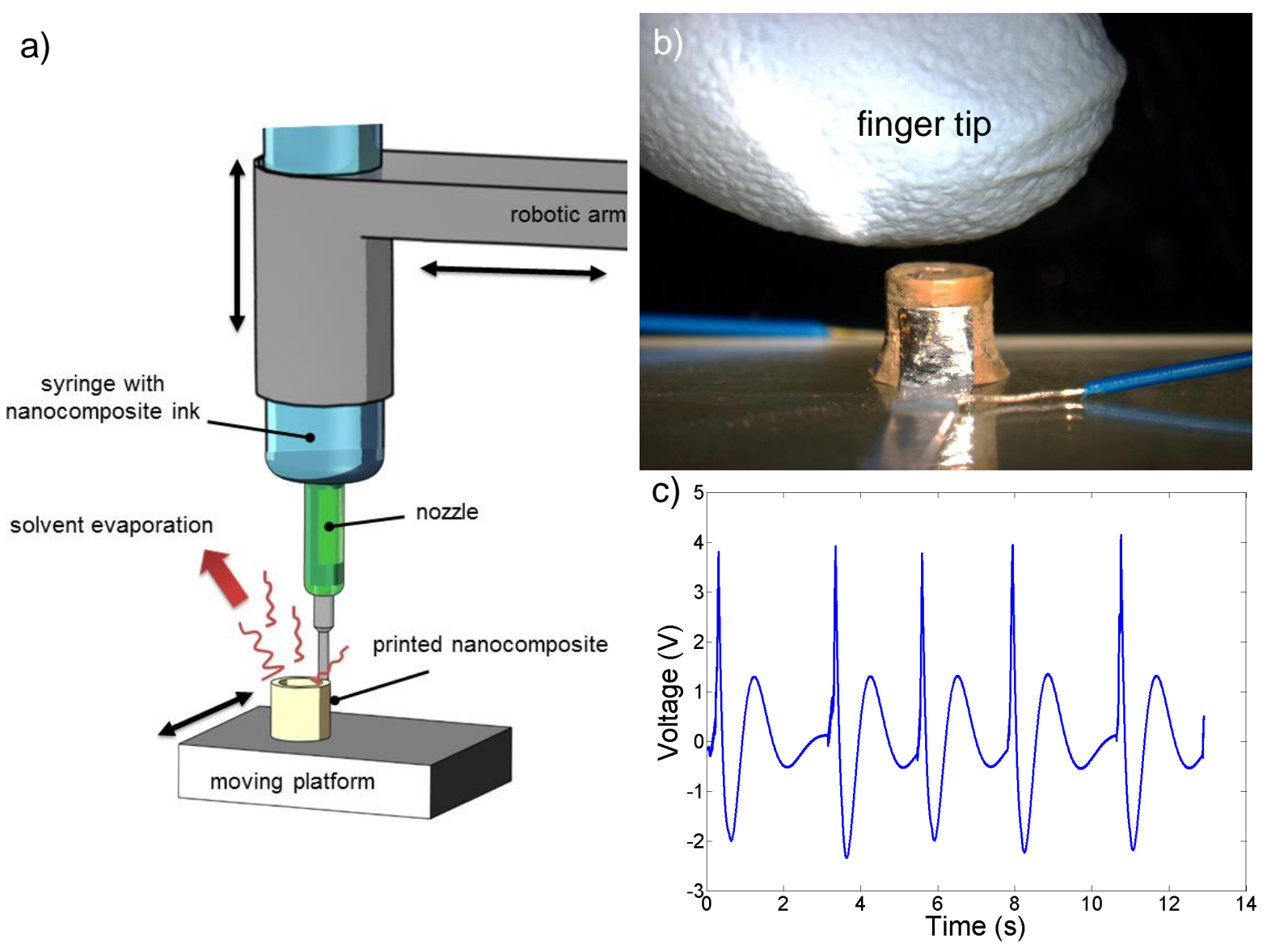

Figure 1. (a) Solvent evaporation-assisted 3D printing process for PVDF nanocomposite-based 3D structures. (b) Photograph of the 3D cylindrical sensor during a finger-tap test. (c) Piezoelectric voltage output of the 3D cylindrical sensor upon five consecutive finger taps. 
a)
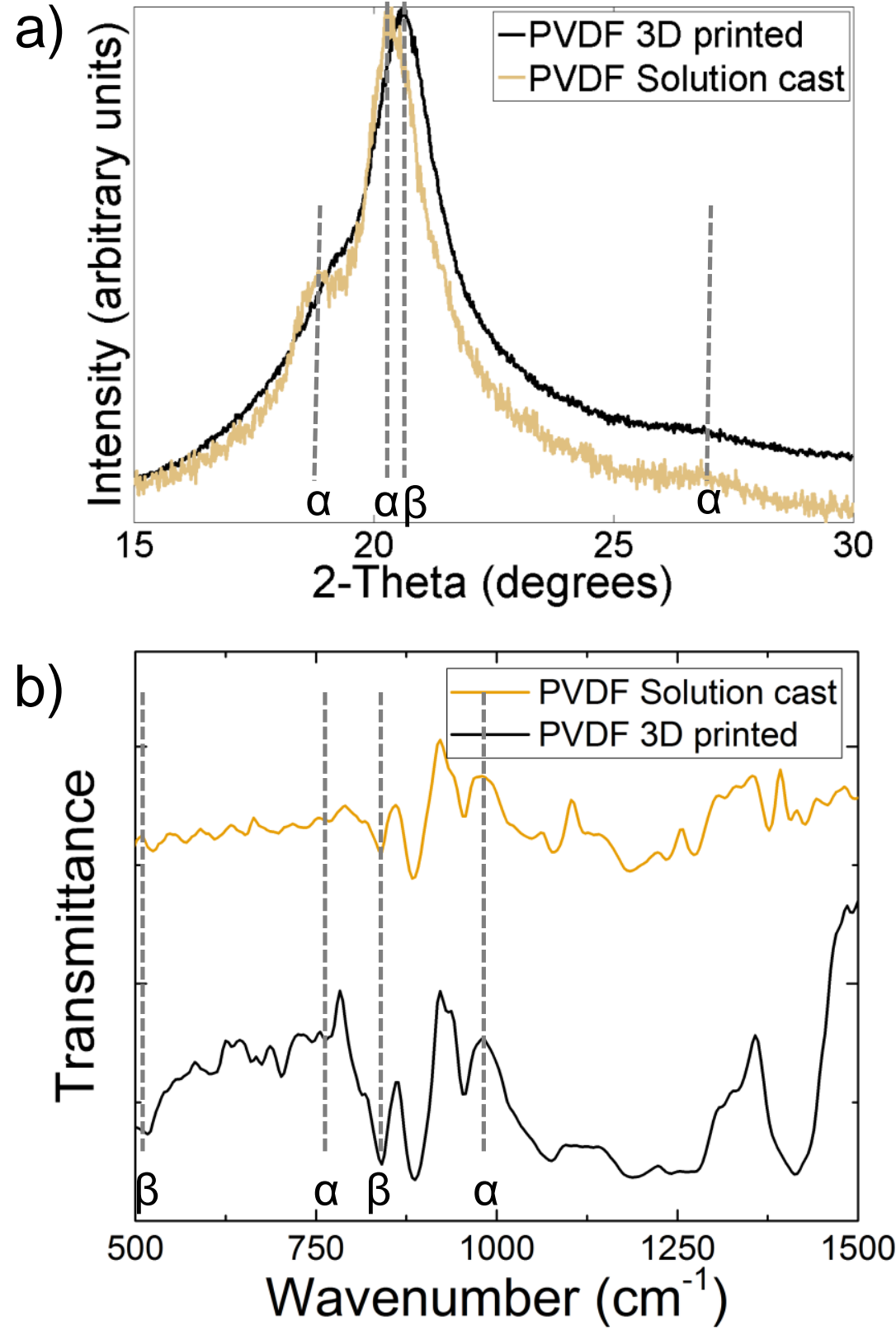

Figure 2. (a) X-ray diffractogram and (b) FTIR curves of 3D printed and solution-cast neat PVDF films (0.2 $\mathrm{g} \mathrm{mL}^{-1}$ of PVDF in solvents). The characteristic peaks of the two phases of PVDF are labeled with their respective symbols $\alpha$ and $\beta$ (printing parameters: $\sim \mathrm{MPa}$ at $20 \mathrm{~mm}$ $\mathrm{s}^{-1}$ with a $100 \mu \mathrm{m}$ nozzle). 

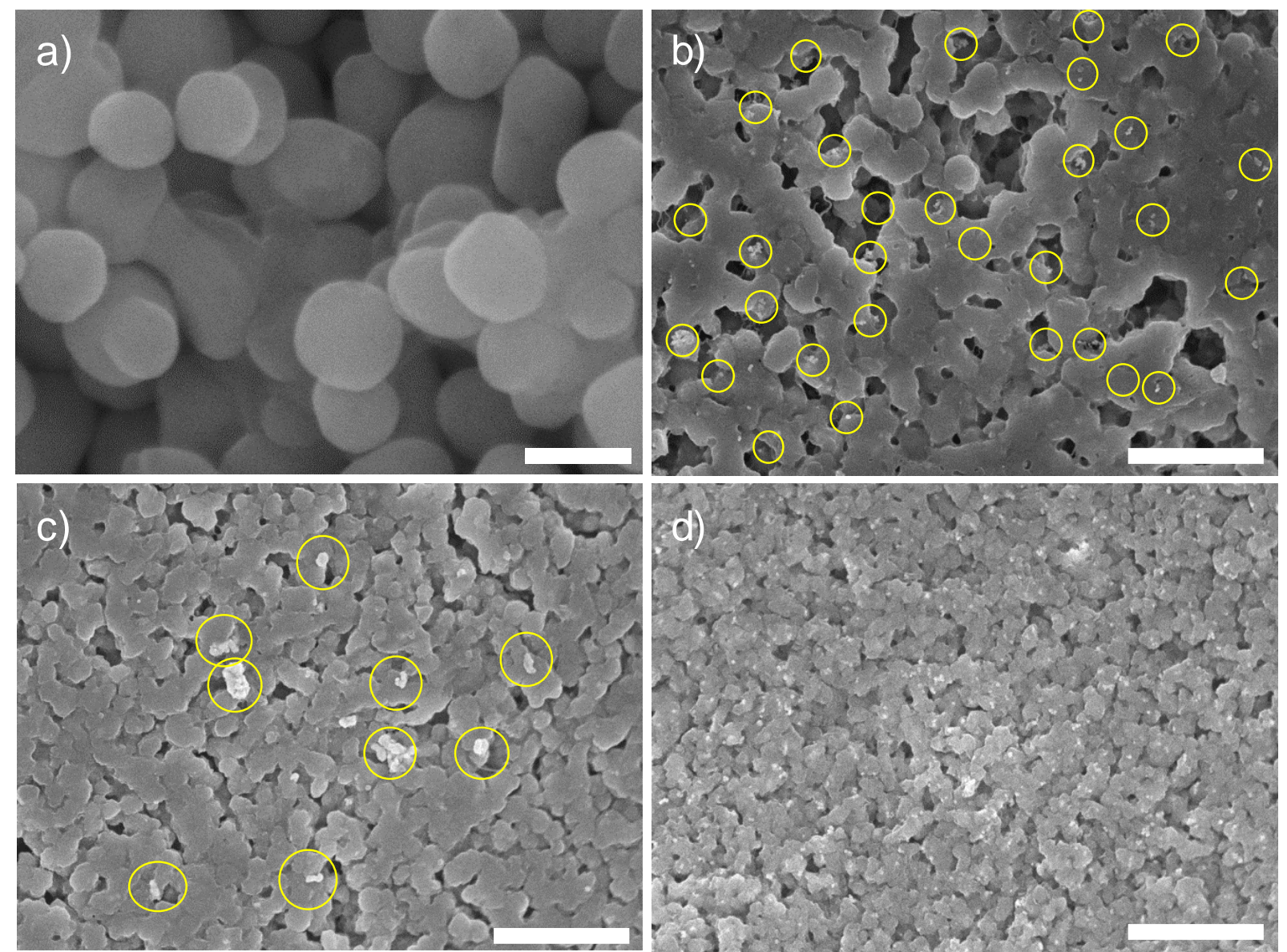

Figure 3. (a) SEM image of $\mathrm{BaTiO}_{3}$ NPs (scale bar $=100 \mathrm{~nm}$ ). SEM images of surfaces of films

fabricated from the $0.2 \mathrm{~g} \mathrm{~mL}^{-1}$ solutions of nanocomposites prepared by (b) ball-milling, (c) extrusion, and (d) sonication (scale bars $=5 \mu \mathrm{m}$ ). Yellow circles highlight the $\mathrm{BaTiO}_{3} \mathrm{NP}$ agglomerates (printing parameters: 1 $\mathrm{MPa}$ at $20 \mathrm{~mm} \mathrm{~s}^{-1}$ with a $100 \mu \mathrm{m}$ nozzle). 

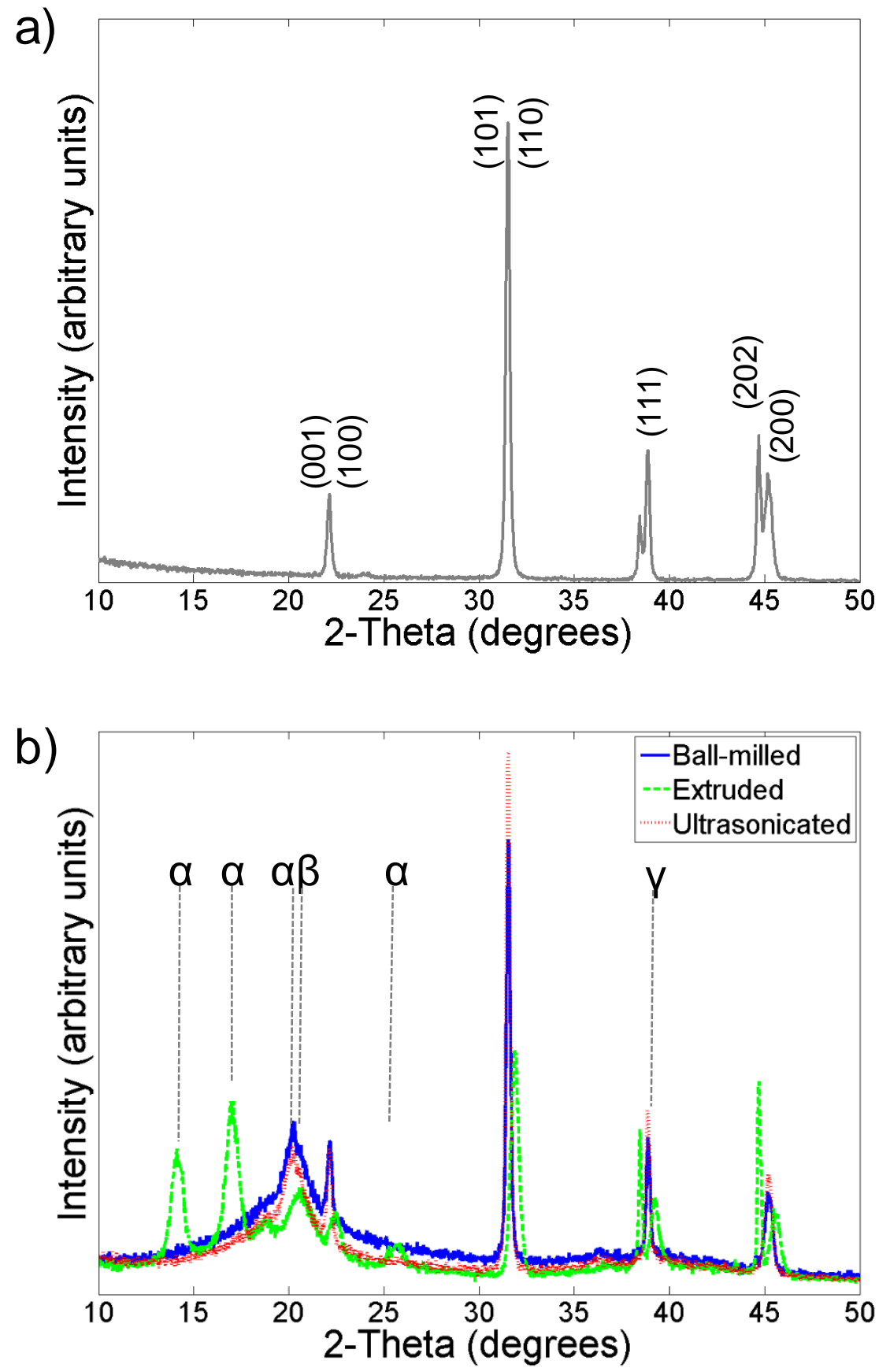

Figure 4. X-ray diffractogram of (a) $\mathrm{BaTiO}_{3} \mathrm{NPs}$ and (b) nanocomposites of 10 wt.\% $\mathrm{BaTiO}_{3}$ NPs and PVDF prepared by ball-milling, extrusion and sonication (printing parameters: $\sim 1 \mathrm{MPa}$ at $20 \mathrm{~mm} \mathrm{~s}^{-1}$ with a $100 \mu \mathrm{m}$ nozzle). 


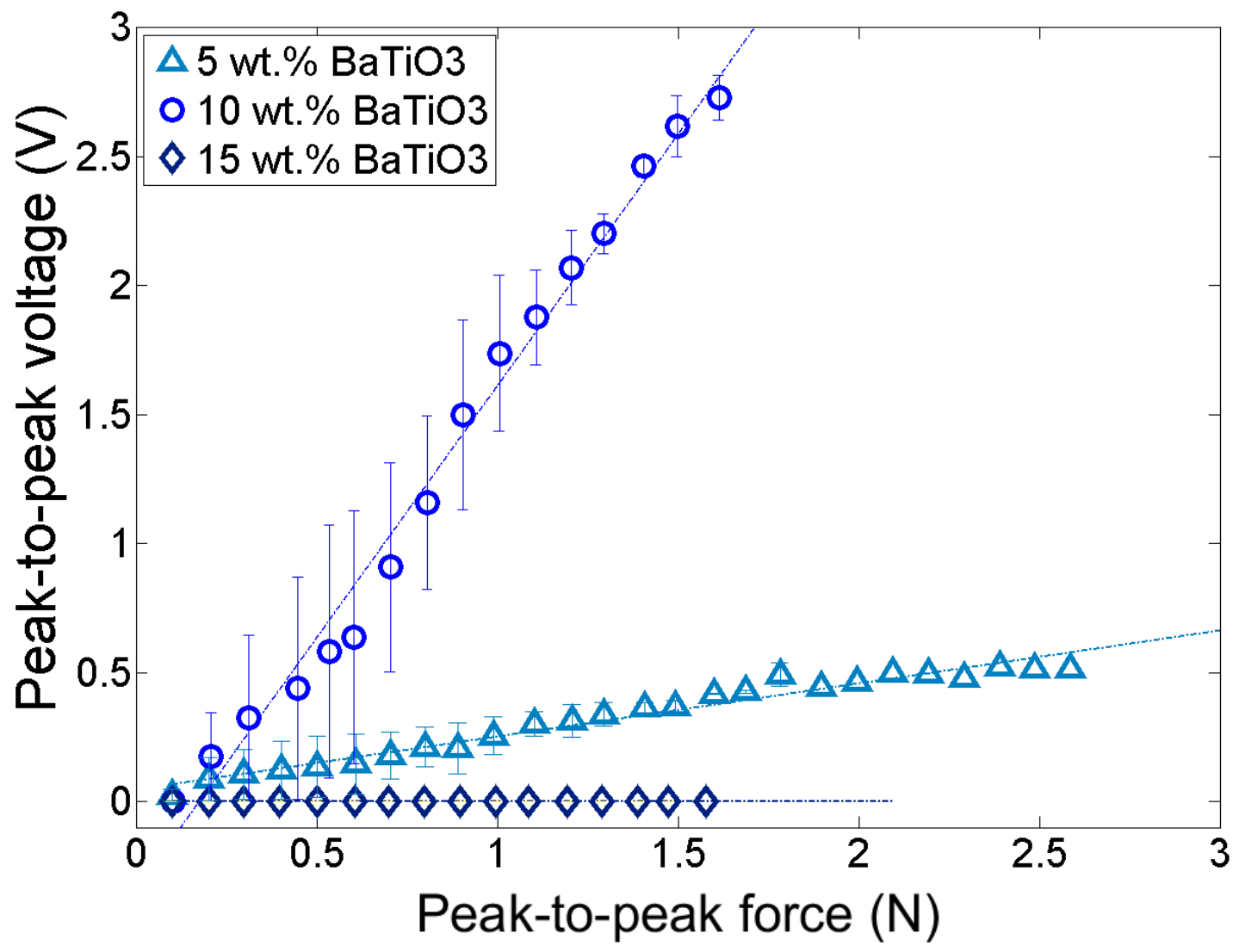

Figure 5. Peak-to-peak voltage as a function of peak force at an excitation frequency of $45 \mathrm{~Hz}$ for 5,10 , and 15 wt. $\%$ of $\mathrm{BaTiO}_{3} \mathrm{NP}$ addition to PVDF via ball-milling. 

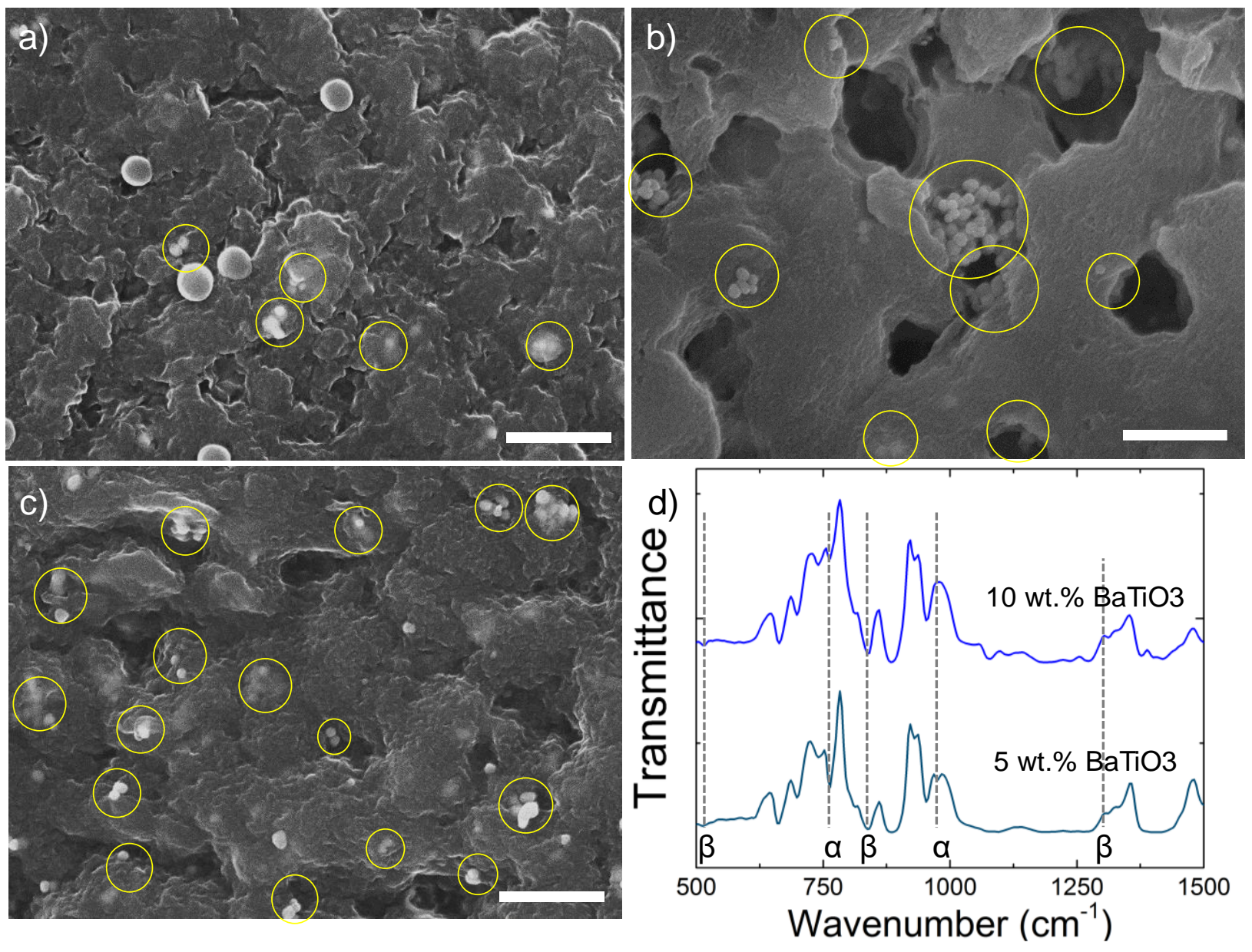

Figure 6: SEM image of surfaces of films fabricated from the $0.2 \mathrm{~g} \mathrm{~mL}^{-1}$ ball-milled nanocomposite solutions of (a) 5 wt.\% $\mathrm{BaTiO}_{3} / 95$ wt.\% PVDF, (b) 10 wt.\% $\mathrm{BaTiO}_{3} / 90$ wt.\% PVDF, (c) 15 wt.\% $\mathrm{BaTiO}_{3} / 85$ wt. \% PVDF (scale bar $=1 \mu \mathrm{m}$ ). Yellow circles highlight $\mathrm{BaTiO}_{3}$ NP agglomerates; (d) FTIR curves of 5 wt.\% $\mathrm{BaTiO}_{3} / 95$ wt.\% PVDF and 10 wt.\% $\mathrm{BaTiO}_{3} / 90$ wt.\% PVDF (printing parameters: 1 $\mathrm{MPa}$ at $20 \mathrm{~mm} \mathrm{~s}^{-1}$ with a $100 \mu \mathrm{m}$ nozzle). 

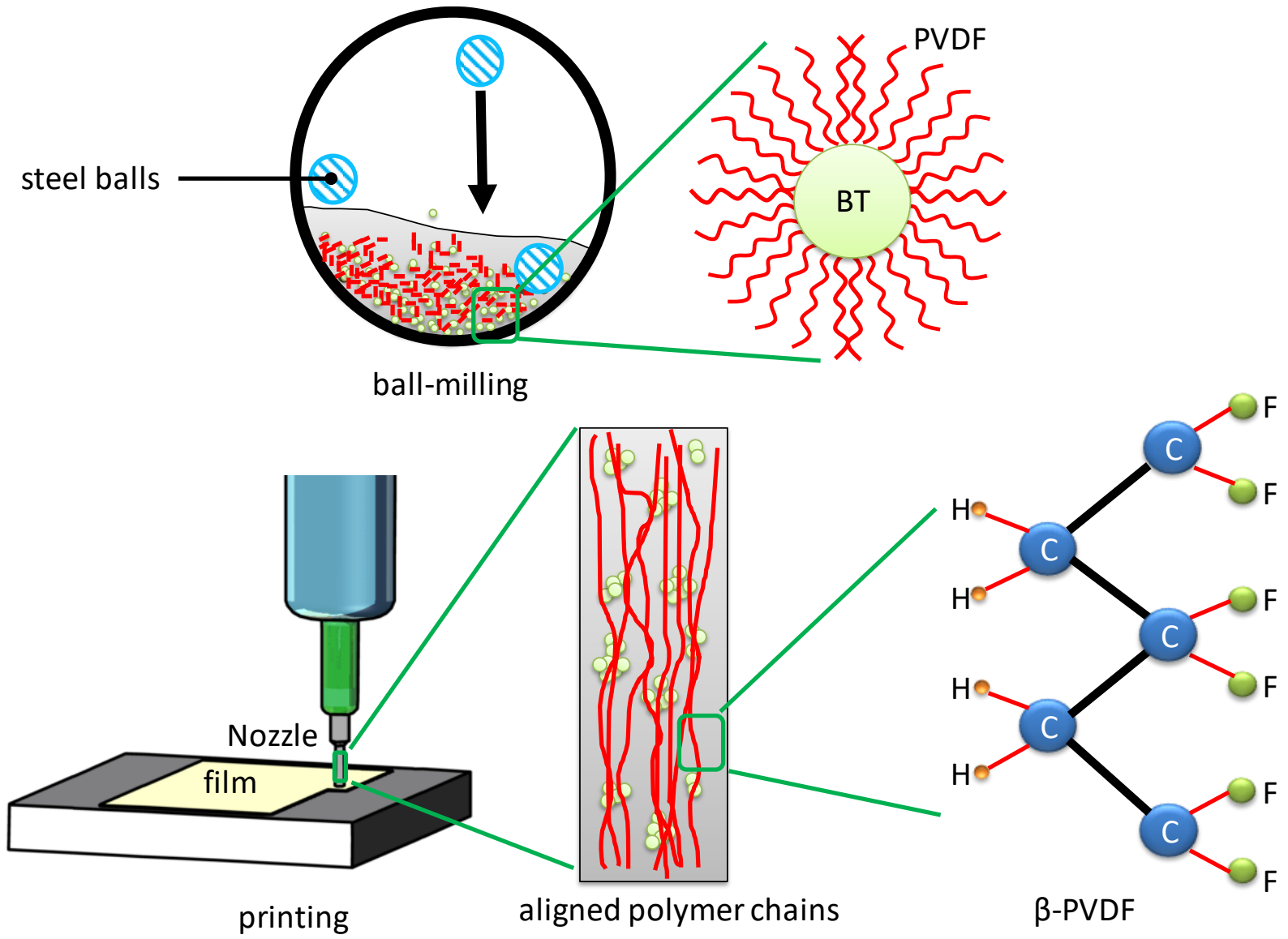

Figure 7. Schematic of the proposed process leading to increase in $\beta$-phase fraction in PVDF due to filler addition. Ball-mill mechanically activates the $\mathrm{BaTiO}_{3} \mathrm{NPs}(\mathrm{BT})$, which provides adhesion sites for PVDF chains. The polymer chains crystallize into aligned $\beta$-phase upon extrusion through the nozzle. The NP agglomerates arrest the PVDF chains in the $\beta$-phase upon solidification, thus leading to improved piezoelectric properties. 


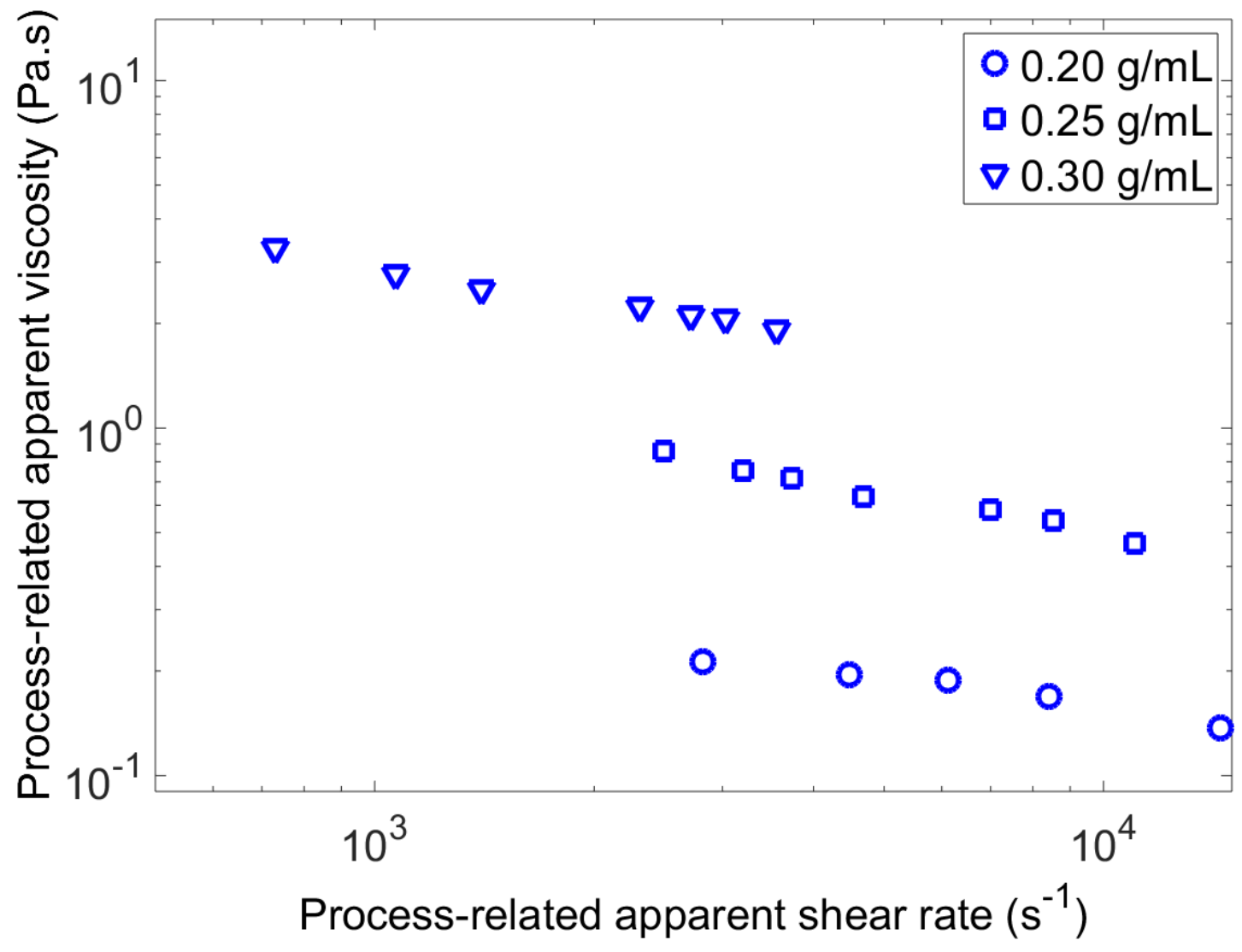

Figure 8. Viscosity as a function of shear rate during the printing process for $0.20,0.25$, and

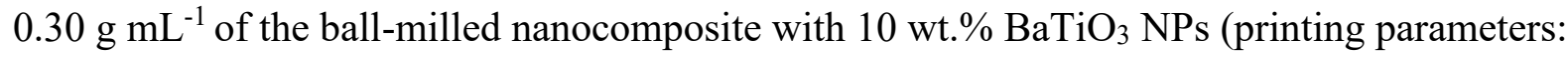
$0.5 \mathrm{~mm} \mathrm{~s}^{-1}$ with a $100 \mu \mathrm{m}$ nozzle). 

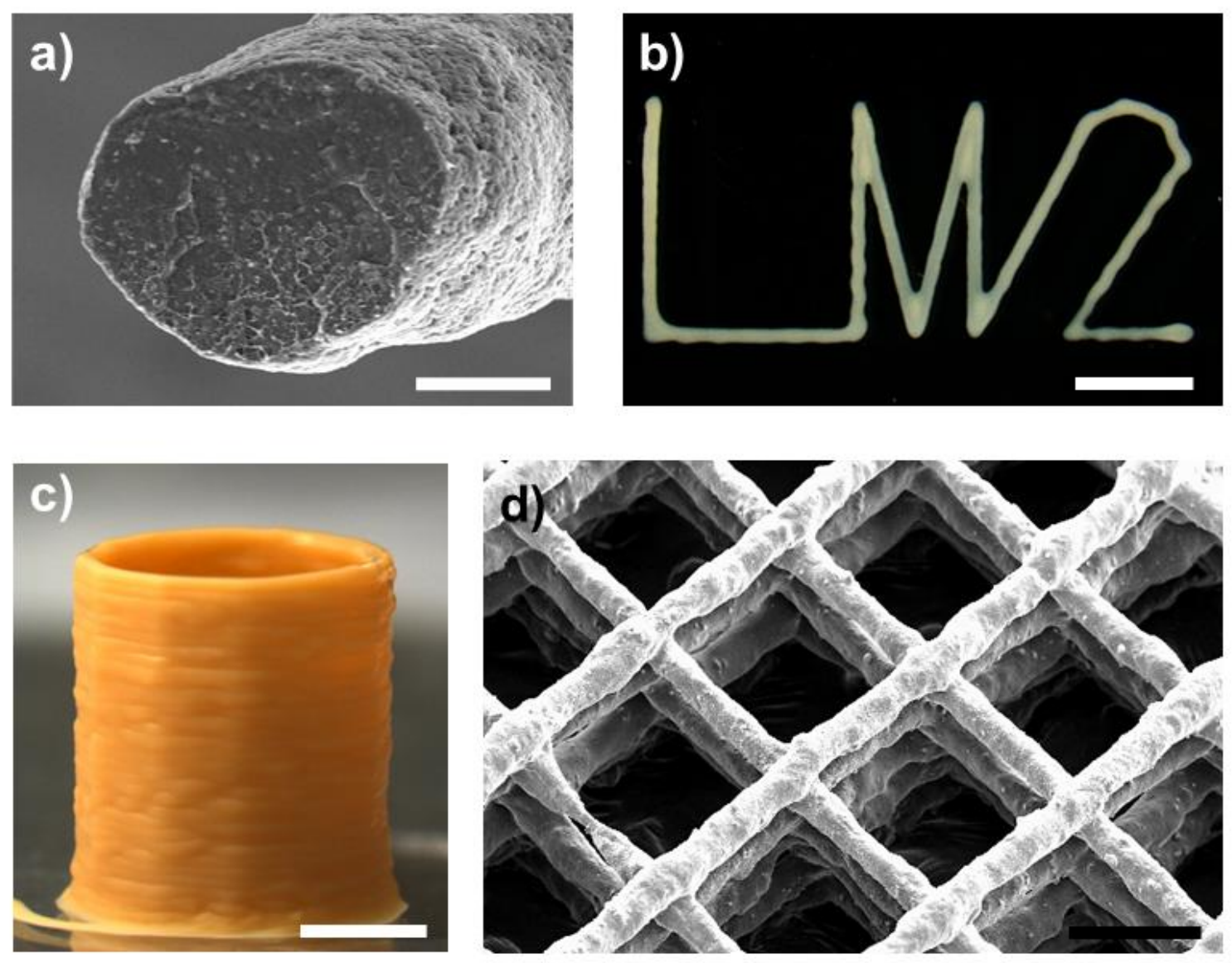

Figure 9. Structures fabricated using $10 \mathrm{wt} . \% \mathrm{BaTiO}_{3}$ ball-milled nanocomposite solution. (a)

SEM image of cross-sectional view of a 1D fiber (scale bar $=25 \mu \mathrm{m}$ ). (b) Optical microscopy image of a 2D structure reading "LM2" (the abbreviation of the Laboratory for Multiscale Mechanics; scale bar $=2.5 \mathrm{~mm}$ ). (c) Photograph of inclined side view of a 2.5D 70-layer circular cylinder (scale bar $=2 \mathrm{~mm}$ ). (d) SEM image of inclined top-view of a 3D spanning 9-layer scaffold (scale bar $=0.5 \mathrm{~mm}$ ). 


\section{ASSOCIATED CONTENT}

Supporting Information. The Supporting Information is available free of charge via the Internet at http://pubs.acs.org." and DOI:

Quasi-static tests and multi-frequency piezoelectric tests with DMA of PVDF nanocomposites; additional information on piezoelectric coefficient calculations; SEM images of the crosssections of films fabricated from ball-milled, extruded, and sonicated nanocomposites; XRD of the films prepared by ball-milling with different NP loadings in PVDF; ferroelectric characterization; apparent viscosity calculation; 3D printed sensor testing (PDF)

\section{AUTHOR INFORMATION}

\section{Corresponding Author}

*daniel.therriault@polymtl.ca

\section{Author Contributions}

The manuscript was written through the contributions of all authors. All authors have given approval to the final version of the manuscript.

\section{ACKNOWLEDGMENT}

The authors acknowledge the financial support from NSERC (Natural Sciences and Engineering Research Council of Canada) and Canada Research Chair. The authors thank the Structures and Composites Materials Laboratory at McGill University for providing access to their DMA apparatus. 


\section{REFERENCES}

1. Pan, C. T.; Hwang, Y. M.; Lin, L.; Chen, Y. C., Design and Fabrication of Self-Powered Micro-Harvesters: Rotating and Vibrated Micro-Power Systems. Wiley: 2014.

2. Lando, J. B.; Olf, H. G.; Peterlin, A., Nuclear Magnetic Resonance and X-Ray Determination of the Structure of Poly(Vinylidene Fluoride). J. Polym. Sci., Part A-1: Polym. Chem. 1966, 4 (4), 941-951.

3. Seok Ju, K.; Youn Jung, P.; Sung, J.; Jo, P. S.; Cheolmin, P.; Kim, K. J.; Cho, B. O., Spin Cast Ferroelectric Beta Poly(Vinylidene Fluoride) Thin Films Via Rapid Thermal Annealing. Appl. Phys. Lett. 2008, 92 (1), 012921-012921-3.

4. $\quad$ Sajkiewicz, P.; Wasiak, A.; Gocłowski, Z., Phase Transitions During Stretching of Poly(Vinylidene Fluoride). Eur. Polym. J. 1999, 35 (3), 423-429.

5. Sencadas, V.; Gregorio, R.; Lanceros-Méndez, S., A to B Phase Transformation and Microestructural Changes of Pvdf Films Induced by Uniaxial Stretch. J. Macromol. Sci., Part B: Phys. 2009, 48 (3), 514-525.

6. $\quad$ Zhang, Y. Y.; Jiang, S. L.; Yu, Y.; Xiong, G.; Zhang, Q. F.; Guang, G. Z., Phase Transformation Mechanisms and Piezoelectric Properties of Poly(Vinylidene Fluoride)/Montmorillonite Composite. J. Appl. Polym. Sci. 2012, 123 (5), 2595-2600. 7. Neumann, G.; Bihler, E.; Eberle, G.; Eisenmenger, W. In Polarization Distribution in Pvdf Obtained by Poling under Constant Current Condition, Electrical Insulation and Dielectric Phenomena, 1990. Annual Report., Conference on, 28-31 Oct 1990; 1990; pp 96-101.

8. Poling and Characterization of Piezoelectric Polymer Fibers for Use in Textile Sensors. Sens. Actuators, A 2013, 201, 477-486.

9. Bodkhe, S.; Rajesh, P. S. M.; Kamle, S.; Verma, V., Beta-Phase Enhancement in Polyvinylidene Fluoride through Filler Addition: Comparing Cellulose with Carbon Nanotubes and Clay. J. Polym. Res. 2014, 21 (5), 1-11.

10. Rajesh, P. S. M.; Bodkhe, S.; Kamle, S.; Verma, V., Enhancing Beta-Phase in Pvdf through Physicochemical Modification of Cellulose. Electron. Mater. Lett. 2014, 10 (1), 315319.

11. Huang, W.; Edenzon, K.; Fernandez, L.; Razmpour, S.; Woodburn, J.; Cebe, P., Nanocomposites of Poly(Vinylidene Fluoride) with Multiwalled Carbon Nanotubes. J. Appl. Polym. Sci. 2010, 115 (6), 3238-3248.

12. Liu, Z. H.; Pan, C. T.; Lin, L. W.; Lai, H. W., Piezoelectric Properties of Pvdf/Mwcnt Nanofiber Using near-Field Electrospinning. Sens. Actuators, A 2013, 193 (0), 13-24.

13. Dillon, D. R.; Tenneti, K. K.; Li, C. Y.; Ko, F. K.; Sics, I.; Hsiao, B. S., On the Structure and Morphology of Polyvinylidene Fluoride-Nanoclay Nanocomposites. Polymer 2006, 47 (5), 1678-1688.

14. Andrew, J. S.; Clarke, D. R., Enhanced Ferroelectric Phase Content of Polyvinylidene Difluoride Fibers with the Addition of Magnetic Nanoparticles. Langmuir 2008, 24 (16), 84358438.

15. Jing, X.; Shen, X.; Song, H.; Song, F., Magnetic and Dielectric Properties of Barium Ferrite Fibers/Poly(Vinylidene Fluoride) Composite Films. J. Polym. Res. 2011, 18 (6), 20172021.

16. Ni, X.; Wang, F.; Lin, A.; Xu, Q.; Yang, Z.; Qin, Y., Flexible Nanogenerator Based on Single Batio3 Nanowire. Sci. Adv. Mater. 2013, 5 (11), 1781-1787. 
17. Yuan, M.; Cheng, L.; Xu, Q.; Wu, W.; Bai, S.; Gu, L.; Wang, Z.; Lu, J.; Li, H.; Qin, Y.; Jing, T.; Wang, Z. L., Biocompatible Nanogenerators through High Piezoelectric Coefficient 0.5ba(Zr0.2ti0.8)O3-0.5(Ba0.7ca0.3)Tio3 Nanowires for in-Vivo Applications. Adv. Mater. 2014, 26 (44), 7432-7437.

18. Mofokeng, T. G. Preparation and Properties of Pvdf Based Batio3 Containing Nanocomposites. University of Free State (Qwaqwa Campus), 2014.

19. Ye, H.-J.; Shao, W.-Z.; Zhen, L., Tetradecylphosphonic Acid Modified Batio3 Nanoparticles and Its Nanocomposite. Colloids Surf., A 2013, 427, 19-25.

20. Luo, X.; Chen, L.; Chen, X.; Huang, Q., Preparation and Electromechanical Properties of Pvdf Matrix Piezoelectric Composites Containing Highly Oriented Batio3 Whiskers. J. Mater. Sci. Technol. 2004, 20 (4), 441-444

21. Zhao, Y.; Liao, Q.; Zhang, G.; Zhang, Z.; Liang, Q.; Liao, X.; Zhang, Y., High Output Piezoelectric Nanocomposite Generators Composed of Oriented Batio3 Nps@Pvdf. Nano Energy 2015, 11, 719-727.

22. Nunes-Pereira, J.; Sencadas, V.; Correia, V.; Cardoso, V. F.; Han, W.; Rocha, J. G.; Lanceros-Méndez, S., Energy Harvesting Performance of Batio3/Poly(Vinylidene FluorideTrifluoroethylene) Spin Coated Nanocomposites. Composites, Part B 2015, 72, 130-136.

23. Valiyaneerilakkal, U.; Varghese, S., Poly (Vinylidene FluorideTrifluoroethylene)/Barium Titanate Nanocomposite for Ferroelectric Nonvolatile Memory Devices. AIP Adv. 2013, 3 (4), 042131.

24. Rajib, M.; Arif Ishtiaque Shuvo, M.; Karim, H.; Delfin, D.; Afrin, S.; Lin, Y., Temperature Influence on Dielectric Energy Storage of Nanocomposites. Ceram. Int. 2015, 41 (1, Part B), 1807-1813.

25. Zhang, L.; Xiao, D.; Ma, J., Dielectric Properties of Pvdf/Ag/Batio3 Composites. Ferroelectrics 2013, 455 (1), 77-82.

26. Lee, D.-H.; Lee, J.-H.; Kim, D.-W.; Kim, B.-K.; Je, H.-J., Enhanced Dielectric Constant of Polymer-Matrix Composites Using Nano-Batio3 Agglomerates. J. Ceram. Soc. Jpn. 2010, 118 (1373), 62-65.

27. Yiin-Kuen, F.; Hsi-Chun, H.; Bo-Sheng, W.; Shan-Chien, L., All-Fiber Transparent Piezoelectric Harvester with a Cooperatively Enhanced Structure. Nanotechnology 2016, 27 (43), 435403.

28. Lee, C.; Tarbutton, J. A., Electric Poling-Assisted Additive Manufacturing Process for Lead-Free Piezoelectric Device Fabrication. Procedia Manufacturing 2015, 1, 320-326.

29. Kim, K.; Zhu, W.; Qu, X.; Aaronson, C.; McCall, W. R.; Chen, S.; Sirbuly, D. J., 3d Optical Printing of Piezoelectric Nanoparticle-Polymer Composite Materials. ACS Nano 2014, 8 (10), 9799-9806.

30. Luo, G.; Teh, K. S.; Liu, Y.; Zang, X.; Wen, Z.; Lin, L., Direct-Write, Self-Aligned Electrospinning on Paper for Controllable Fabrication of Three-Dimensional Structures. ACS Appl. Mater. Interfaces 2015, 7 (50), 27765-27770.

31. Pu, J.; Yan, X.; Jiang, Y.; Chang, C.; Lin, L., Piezoelectric Actuation of Direct-Write Electrospun Fibers. Sens. Actuators, A 2010, 164 (1-2), 131-136.

32. Guo, S. Z.; Gosselin, F.; Guerin, N.; Lanouette, A. M.; Heuzey, M. C.; Therriault, D., Solvent-Cast Three-Dimensional Printing of Multifunctional Microsystems. Small 2013, 9 (24), 4118-22.

33. Guo, S.-Z.; Heuzey, M.-C.; Therriault, D., Properties of Polylactide Inks for Solvent-Cast Printing of Three-Dimensional Freeform Microstructures. Langmuir 2014, 30 (4), 1142-1150. 
34. A13547 N,N-Dimethylformamide, 99\%. (R), A. A., Ed.

35. Benz, M.; Euler, W. B.; Gregory, O. J., The Role of Solution Phase Water on the Deposition of Thin Films of Poly(Vinylidene Fluoride). Macromolecules 2002, 35 (7), 26822688.

36. Poly(Vinylidene Fluoride).

37. John, M. D., Elements of Rheology. In Polymer Processing Instabilities, CRC Press: 2004, pp 13-42.

38. Bruneaux, J.; Therriault, D.; Heuzey, M.-C., Micro-Extrusion of Organic Inks for DirectWrite Assembly. J. Micromech. Microeng. 2008, 18, 11.

39. Kontos, G. A.; Soulintzis, A. L.; Karahaliou, P. K.; Psarras, G. C.; Georga, S. N.; Krontiras, C. A.; Pisanias, M. N., Electrical Relaxation Dynamics in Tio2 - Polymer Matrix Composites. eXPRESS Polym. Lett. 2007, 1 (12), 781-789.

40. Roy, M.; Nelson, J. K.; MacCrone, R. K.; Schadler, L. S.; Reed, C. W.; Keefe, R., Polymer Nanocomposite Dielectrics-the Role of the Interface. IEEE Trans. Dielectr. Electr. Insul. 2005, 12 (4), 629-643.

41. Zhang, C.; Chi, Q.; Dong, J.; Cui, Y.; Wang, X.; Liu, L.; Lei, Q., Enhanced Dielectric Properties of Poly(Vinylidene Fluoride) Composites Filled with Nano Iron Oxide-Deposited Barium Titanate Hybrid Particles. Sci. Rep. 2016, 6, 33508.

42. Bodkhe, S.; Gosselin, F. P.; Therriault, D. In Three-Dimensional Printing of Polyvinylidene Fluoride Nanocomposites, 20th International Conference on Composite Materials, Copenhagen, Denmark, 19-24th July 2015 International comittee on composite materials: Copenhagen, Denmark, 2015; p 9.

43. Martins, P.; Lopes, A. C.; Lanceros-Mendez, S., Electroactive Phases of Poly(Vinylidene Fluoride): Determination, Processing and Applications. Prog. Polym. Sci. 2014, 39 (4), 683-706. 44. Huang, S.; Yee, W. A.; Tjiu, W. C.; Liu, Y.; Kotaki, M.; Boey, Y. C. F.; Ma, J.; Liu, T.; Lu, X., Electrospinning of Polyvinylidene Difluoride with Carbon Nanotubes: Synergistic Effects of Extensional Force and Interfacial Interaction on Crystalline Structures. Langmuir 2008, 24 (23), 13621-13626.

45. Yu, S.; Zheng, W.; Yu, W.; Zhang, Y.; Jiang, Q.; Zhao, Z., Formation Mechanism of BPhase in Pvdf/Cnt Composite Prepared by the Sonication Method. Macromolecules 2009, 42 (22), 8870-8874.

46. Shah, D.; Maiti, P.; Gunn, E.; Schmidt, D. F.; Jiang, D. D.; Batt, C. A.; Giannelis, E. P., Dramatic Enhancements in Toughness of Polyvinylidene Fluoride Nanocomposites Via Nanoclay-Directed Crystal Structure and Morphology. Adv. Mater. 2004, 16 (14), 1173-1177. 47. Dineva, P.; Gross, D.; Müller, R.; Rangelov, T., Piezoelectric Materials. In Dynamic Fracture of Piezoelectric Materials: Solution of Time-Harmonic Problems Via Biem, Springer International Publishing: Cham, 2014, pp 7-32.

48. Niu, Y.; Yu, K.; Bai, Y.; Wang, H., Enhanced Dielectric Performance of Batio3/Pvdf Composites Prepared by Modified Process for Energy Storage Applications. IEEE Trans. Sonics Ultrason. 2015, 62 (1), 108-115.

49. Nayak, S.; Sahoo, B.; Chaki, T. K.; Khastgir, D., Facile Preparation of Uniform Barium Titanate (Batio3) Multipods with High Permittivity: Impedance and Temperature Dependent Dielectric Behavior. RSC Adv. 2014, 4 (3), 1212-1224.

50. Yamashita, Y.; Tada, M.; Kakihana, M.; Osada, M.; Yoshida, K., Synthesis of Ruo2Loaded Batino2n $+1(\mathrm{~N}=1,2$ and 5) Using a Polymerizable Complex Method and Its 
Photocatalytic Activity for the Decomposition of Water. J. Mater. Chem. 2002, 12 (6), 17821786.

51. Thakur, V. K.; Yan, J.; Lin, M.-F.; Zhi, C.; Golberg, D.; Bando, Y.; Sim, R.; Lee, P. S., Novel Polymer Nanocomposites from Bioinspired Green Aqueous Functionalization of Bnnts. Polym. Chem. 2012, 3 (4), 962-969.

52. Gaur, M. S.; Singh, P.; Ali, A.; Singh, R., Thermally Stimulated Discharge Current (Tsdc) Characteristics in B-Phase Pvdf-Batio3 Nanocomposites. J. Therm. Anal. Calorim. 2014, 117 (3), 1407-1417.

53. Pramoda, K. P.; Mohamed, A.; Yee Phang, I.; Liu, T., Crystal Transformation and Thermomechanical Properties of Poly(Vinylidene Fluoride)/Clay Nanocomposites. Polym. Int. 2005, 54 (1), 226-232.

54. Lin, M.-F.; Lee, P. S., Formation of Pvdf-G-Hema/Batio3 Nanocomposites Via in Situ Nanoparticle Synthesis for High Performance Capacitor Applications. J. Mater. Chem. A 2013, 1 (46), 14455-14459.

55. Sánchez, F. A.; Redondo, M.; González-Benito, J., Influence of Batio3 Submicrometric Particles on the Structure, Morphology, and Crystallization Behavior of Poly(Vinylidene Fluoride). J. Appl. Polym. Sci. 2015, 132 (8), 41497(1-10).

56. Fu, D.; Itoh, M., Role of Ca Off-Centering in Tuning Ferroelectric Phase Transitions in Ba(Zr,Ti)O3system. 2015.

57. Division, S. P. Piezo Film Sensors Technical Manual; Measurement Specialties, Inc: Norristown, PA 1999.

58. Gan, W. C.; Majid, W. H. A., Effect of Tio 2 on Enhanced Pyroelectric Activity of Pvdf Composite. Smart Mater. Struct. 2014, 23 (4), 045026.

59. Ploss, B.; Ng, W.-Y.; Chan, H. L.-W.; Ploss, B.; Choy, C.-L., Poling Study of Pzt/P(VdfTrfe) Composites. Compos. Sci. Technol. 2001, 61 (7), 957-962.

60. Sirohi, J.; Chopra, I. In Fundamental Understanding of Piezoelectric Strain Sensors, 1999; pp 528-542.

61. Pavlović, V. P.; Pavlović, V. B.; Vlahović, B.; Božanić, D. K.; Pajović, J. D.; Dojčilović, R.; Djoković, V., Structural Properties of Composites of Polyvinylidene Fluoride and Mechanically Activated Batio 3 Particles. Phys. Scr. 2013, 2013 (T157), 014006.

62. Pavlović, V. P.; Popović, D.; Krstić, J.; Dojčilović, J.; Babić, B.; Pavlović, V. B., Influence of Mechanical Activation on the Structure of Ultrafine Batio3 Powders. J. Alloys Compd. 2009, 486 (1-2), 633-639.

63. Mendes, S. F.; Costa, C. M.; Caparros, C.; Sencadas, V.; Lanceros-Méndez, S., Effect of Filler Size and Concentration on the Structure and Properties of Poly(Vinylidene

Fluoride)/Batio3 Nanocomposites. J Mater Sci 2012, 47 (3), 1378-1388.

64. Nunes-Pereira, J.; Sencadas, V.; Correia, V.; Rocha, J. G.; Lanceros-Méndez, S., Energy Harvesting Performance of Piezoelectric Electrospun Polymer Fibers and Polymer/Ceramic Composites. Sens. Actuators, A 2013, 196, 55-62.

65. Kraft, D. A. Polymer Orientation.

http://www.che.hw.ac.uk/teaching/B11MS1/Material/Processing/Orient.htm (accessed 13 January 2017).

66. Yao, J.; Bastiaansen, C.; Peijs, T., High Strength and High Modulus Electrospun Nanofibers. Fibers 2014, 2 (2), 158.

67. Carreau, P. J.; De Kee, D.; Chhabra, R. P., Rheology of Polymeric Systems: Principles and Applications. Hanser Publishers: 1997. 
68. Compton, B. G.; Lewis, J. A., 3d-Printing of Lightweight Cellular Composites. Adv. Mater. 2014, 26 (34), 5930-5935.

69. Correia, D. M.; Ribeiro, C.; Sencadas, V.; Vikingsson, L.; Oliver Gasch, M.; Gómez Ribelles, J. L.; Botelho, G.; Lanceros-Méndez, S., Strategies for the Development of Three

Dimensional Scaffolds from Piezoelectric Poly(Vinylidene Fluoride). Mater. Des. 2016, 92, 674681. 
Table of Contents Graphic

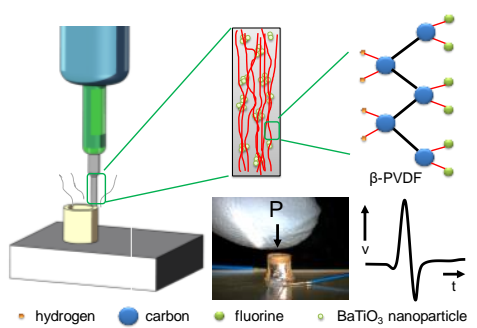

